\title{
Stereocontrolled spirocyclization of exo-glucal derivatives for stereodivergent synthesis of spiro[5.5]ketals
}

\author{
Sho Matsuda, ${ }^{\mathrm{a}, \mathrm{b}}$ Akihiro Yoshida, ${ }^{\mathrm{a}}$ Junki Nakagawa, ${ }^{\mathrm{b}}$ Mikio Watanabe, ${ }^{\mathrm{b}}$ Yoshiki Oda, ${ }^{\mathrm{a}}$ and \\ Takashi Yamanoi ${ }^{\mathrm{c}, *}$ \\ ${ }^{a}$ The Noguchi Institute, 1-8-1 Kaga, Itabashi-ku, Tokyo 173-0003, Japan \\ ${ }^{b}$ Department of Chemistry, School of Science, Tokai University, 4-1-1 Kitakaname, Hiratsuka, Kanagawa 259-1292, Japan \\ ${ }^{c}$ Faculty of Pharmaceutical Sciences, Josai University, 1-1 Keyakidai, Sakado, Saitama 350-0295, Japan
}

ABSTRACT- This paper describes a stereoselective synthetic approach to spiro[5.5]ketals from the exo-glucals, constructed from 1-(4-hydroxyalkylidene)-1,5-anhydro-D-glucitol, by spirocyclization based on intramolecular $\alpha$ - and $\beta$-selective glycosylation. Stereodivergent synthesis of both $\alpha$ - and $\beta$-glucoside of spiro[5.5]ketals was attained by combination of chiral D-glucopyranose environment and C-4' chiral center on the side chain.

exo-Glycals are enol ether derivatives of sugars and useful intermediates for preparing more elaborate compounds in carbohydrate chemistry. ${ }^{1}$ They are susceptible to nucleophilic attack by an alcohol in the presence of an acid catalyst to readily form $O$-ketosides. ${ }^{2}$ Recent attention has been focused on the formation of spiro-fused $O$-ketosides, i.e. spiroketals, from glycals with an appropriate side chain by spirocyclization based on intramolecular glycosylation (Scheme 1). ${ }^{3}$

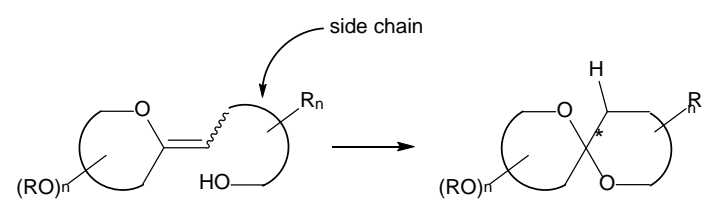

Sheme 1. Lewis acid-promoted cyclization of exo-glucal to yield spiro[5.5]ketal.

The glycals can be changed into various optically active spiroketals with original carbohydrate skeletons. Some of them are useful building blocks for synthesizing spiroketal fragments in naturally occurring products of marine, insect and bacterial origins. ${ }^{4}$ One of the major problems in synthetic approaches to spiroketals from glycals is the synthetic difficulty in creating the appropriate glycals for spirocyclization. ${ }^{3}$ It is also necessary to clarify the spirocyclization properties of the glycals.

Our recent study showed a novel synthetic approach to exo-glucals 2-4 by reactions of 1-C-vinylated D-glucopyranose 1 with silyl enolates in the presence of trimethylsilyl trifluoromethanesulfonate. ${ }^{5}$ We investigated the preparation of the exo-glucals 5-8 from 2-4 for spirocyclization (Scheme 2). The C-4' carbonyl groups of the exo-glucals 2-4 were converted into the corresponding alcohol derivatives using $\mathrm{NaBH}_{4}$ in THF/MeOH $(\mathrm{v} / \mathrm{v}=5 / 1)$ at $0{ }^{\circ} \mathrm{C}$, K-Selectride ${ }^{\circledR}$ in $\mathrm{THF}$ at $-78{ }^{\circ} \mathrm{C}$ and methyllithium in THF at $-78{ }^{\circ} \mathrm{C}$. Table 1 shows the results. The desired exo-glycals 5-8 were produced in yields of 67-86\%, and the diastereomer ratios ( $R / S$ at C-4') of 6-8 ranged from $47 / 53$ to 59/41. We conveniently produced all the both C-4' isomers by chromatography separation. The absolute configurations at C-4' of 6-8 were determined by the modified Mosher's method. ${ }^{6}$

First, we investigated the synthesis of the spiro[5.5]ketals by spirocyclization of $\mathbf{5}$ with achiral alcohol on the side chain based on intramolecular glycosylation (Schemes 3). We carried out the spirocyclizations using $\mathrm{BF}_{3} \cdot \mathrm{OEt}_{2}(1$ equiv.) as an activator in $\mathrm{CH}_{2} \mathrm{Cl}_{2}$ at $0{ }^{\circ} \mathrm{C}$ for $1 \mathrm{~h}$. Compound 5 was smoothly spirocyclized through intramolecular $\alpha$-attack to give a spiroketal (1S)-9 in 91\% yield as a single isomer. Thus, we found that the chiral glucopyranose environment made C-4' alcohol differentiate between both diastereofaces of oxocarbenium and attack from the $\alpha$-face. The $\alpha$-attack product (1S)-9 was stable due to the "double" anomeric effects. Considering the reaction mechanism, $\alpha$-attack is also more favorable than $\beta$-attack because of the unstable twist boat/chair intermediate just after $\beta$-attack (Figure 1). 


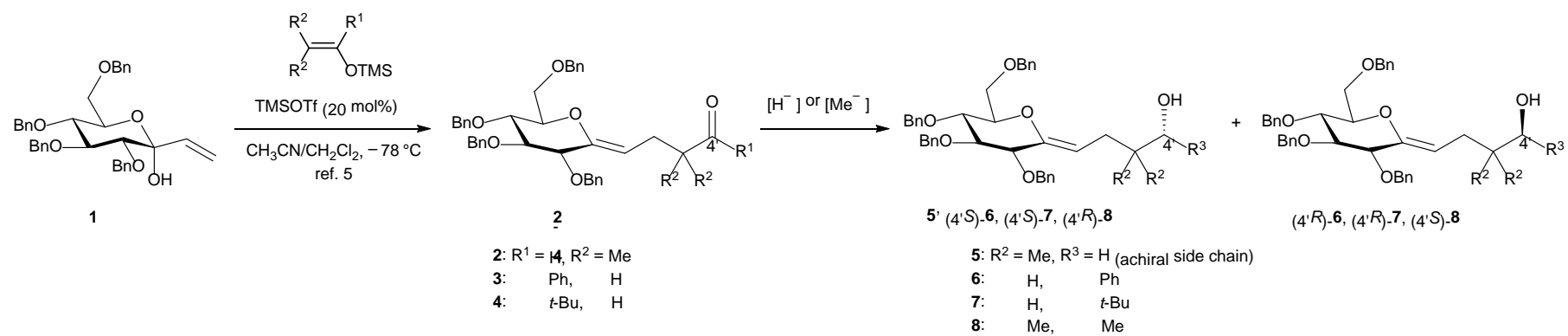

Scheme 2. Synthesis of exo-glucals for spirocyclization.

Table 1. Synthesis of exo-glucals for spirocyclization.

\begin{tabular}{|c|c|c|c|c|c|c|c|c|}
\hline \multirow{2}{*}{$\begin{array}{l}\text { Entr } \\
\mathrm{y}\end{array}$} & \multicolumn{3}{|c|}{ Starting exo-glucal } & \multirow{2}{*}{ Reagents and conditions } & \multicolumn{4}{|c|}{ Produced exo-glucal } \\
\hline & & $\mathrm{R}^{1}$ & $\mathrm{R}^{2}$ & & & $\mathrm{R}^{2}$ & $\mathrm{R}^{3}$ & Yield/\% (ratio) \\
\hline 1 & 2 & $\mathrm{H}$ & $\mathrm{Me}$ & $\mathrm{NaBH}_{4}, \mathrm{THF} / \mathrm{MeOH}(5 / 1), 0^{\circ} \mathrm{C}$ & 5 & $\mathrm{Me}$ & $\mathrm{H}$ & 79 \\
\hline 2 & 3 & $\mathrm{Ph}$ & $\mathrm{H}$ & $\mathrm{NaBH}_{4}, \mathrm{THF} / \mathrm{MeOH}(5 / 1), 0^{\circ} \mathrm{C}$ & $\left(4^{\prime} S\right)-\&\left(4^{\prime} R\right)-6$ & $\mathrm{H}$ & $\mathrm{Ph}$ & $73(47 / 53)$ \\
\hline 3 & 3 & $\mathrm{Ph}$ & $\mathrm{H}$ & $\mathrm{K}$-selectride ${ }^{\circledR}, \mathrm{THF},-78^{\circ} \mathrm{C}$ & $\left(4^{\prime} S\right)-\&\left(4^{\prime} R\right)-6$ & $\mathrm{H}$ & $\mathrm{Ph}$ & $74(59 / 41)$ \\
\hline 4 & 4 & $t-\mathrm{Bu}$ & $\mathrm{H}$ & $\mathrm{NaBH}_{4}, \mathrm{THF} / \mathrm{MeOH}(5 / 1), 0{ }^{\circ} \mathrm{C}$ & $\left(4^{\prime} S\right)-\&\left(4^{\prime} R\right)-7$ & $\mathrm{H}$ & $t-\mathrm{Bu}$ & $86(54 / 46)$ \\
\hline 5 & 2 & $\mathrm{H}$ & $\mathrm{Me}$ & $\mathrm{MeLi}, \mathrm{THF},-78^{\circ} \mathrm{C}$ & $\left(4^{\prime} R\right)-\&\left(4^{\prime} S\right)-8$ & $\mathrm{Me}$ & $\mathrm{Me}$ & $67(48 / 52)$ \\
\hline
\end{tabular}

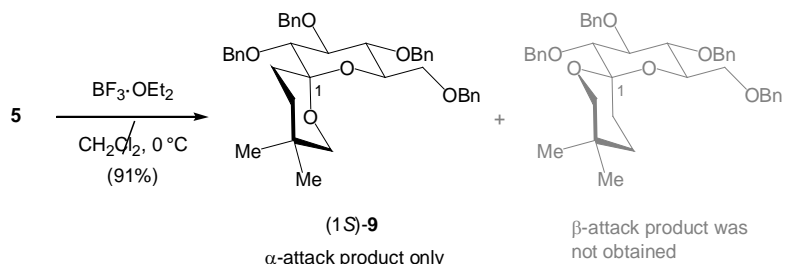

Scheme 3. Spirocyclization of the substrate 5 with achiral side chain

It is difficult to attack from $\beta$-side particularly in the case of ketopyranose. ${ }^{7}$ We think that $\beta$-attack product can be obtained when a suit combination of the chiral glucopyranose and chiral alcohol on the side chain is used. The chiral glucopyranose gave $\alpha$-attack product in the previous experiment using the substrate $\mathbf{5}$. When the chiral alcohol environment on the side chain gives $\alpha$-attack product, it is expected to obtain $\alpha$-attack product only. This case corresponds to the matched pair in the double asymmetric induction. ${ }^{8}$ In order to obtain $\beta$-attack product, the chiral alcohol environment on the side chain must have a strong force for $\beta$-attack. This case corresponds to the mismatched pair in the double asymmetric

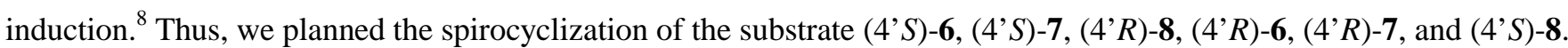

We predicted the stereoselectivity of the spirocyclization before the experiments. Considering the reaction mechanism, it appears that $\mathrm{BF}_{3}$ is preferentially coordinated to the oxygen of hydroxyl than those of benzyloxy groups. Thus, $\mathrm{BF}_{3}$ accelerates the protonation to the vinyl ether moiety to form the oxocarbenium ion, which was the key intermediate for spirocyclization. One epimer, which corresponds to $(R)$-alcohol as described above, can be cyclized through a six-membered ring transition state (A) in which the C-4' R-substituent possesses an equatorial orientation to afford the $\alpha$-attack product (Figure 2). ${ }^{9}$ Stereoelectronic effect of the interaction between $n_{\mathrm{O}}$ at the axial position of the six-membered ring transition state and $\sigma^{*}{ }_{\mathrm{C}=\mathrm{O}^{+}}$also stabilizes the transition state (A). When $\beta$-attack occurs, the C-4' R-substituent is at a disfavored axial position. In contrast, spirocyclization of the other epimer, which corresponds to (S)-alcohol as described above, can be unfavorable through a similar transition state (B-1) that includes the C-4' R-substituent at the axial position because of 1,3-diaxial repulsion. In the case of the transition state (B-2), the $\alpha$-attack occurs with difficulty because of severe steric hindrance due to the existence of the C-2 benzyloxy function despite the presence of C-4' R-substituent at the 
equatorial position. In addition, the transition state (B-2) is not stabilized by interaction between axial $n_{\mathrm{O}}$ and $\sigma^{*}{ }_{\mathrm{C}=\mathrm{O}^{+}}$. Thus, we predicted that the $\beta$-attack, which is essentially unfavorable (in the case of spirocyclization of 5), may preferentially occur via the transition state (B-3). It would appear that the reaction proceeds through the similar route as drawn on the right side of Figure 2 to afford the $\beta$-attack product.

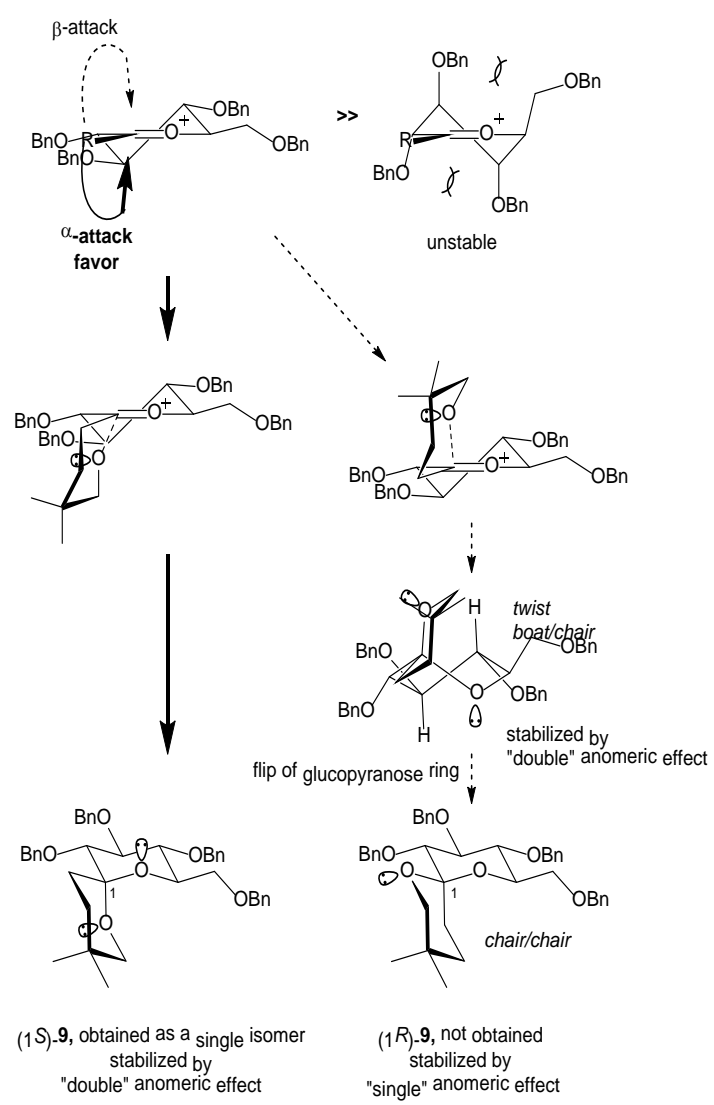

Figure 1. Proposed reaction mechanism of spirocyclization of the substrate 5 to yield (1S)-9.

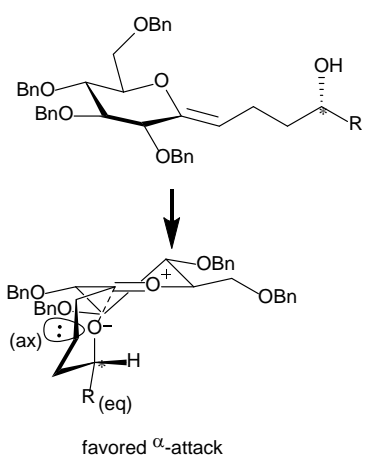

(A)

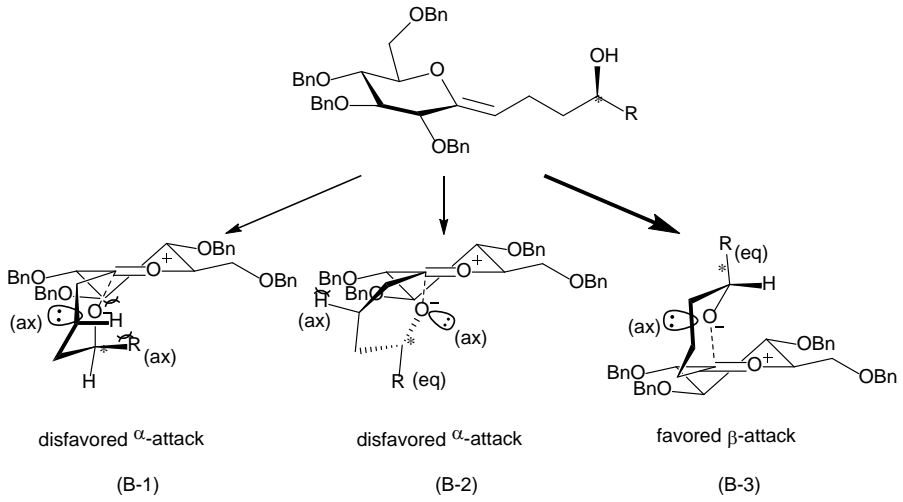

(B-1)

(B-2)

(B-3)

Figure 2. Proposed transition state of spirocyclization of exo-glucals

Considering stability of the spirocyclized products, the product A-eq-w from the transition state $\mathbf{A}$ is much more stable than the product A-ax-s due to the $\mathrm{R}^{3}$-substituent at the equatorial position and the double anomeric effects (Figure 3 ). On the other hand, it appears that the product $\mathbf{B}-\mathbf{a x}-\mathbf{s}\left(\mathrm{R}^{3}\right.$-substituent at the axial position and double anomeric effects) from the transition state $\mathbf{B}-\mathbf{1}$ or $\mathbf{B}-\mathbf{2}$ is almost as stable as the product $\mathbf{B}$-eq-s $\left(\mathrm{R}^{3}\right.$-substituent at the equatorial position and single anomeric effect) from the transition state B-3. Deslongchamps and coworkers have reported the spirocyclization to 2-methyl-1,7-dioxaspiro[5.5]undecane. ${ }^{10}$ This report can be the model study for our spirocyclization. According to this report, the relative stability of the four isomers is as follows: A-eq-w type ( $0 \mathrm{kcal} / \mathrm{mol})$, A-ax-s type $(2.4 \mathrm{kcal} / \mathrm{mol}), \mathbf{B}-\mathbf{a x}-\mathbf{w}$ 
type $(2.9 \mathrm{kcal} / \mathrm{mol})$, and B-eq-s $(2.4 \mathrm{kcal} / \mathrm{mol})$. In this experimental study,.spirocyclized products were A-eq-w and the enantiomer of A-eq-w. We are interested how stereoselectivity changes when exo-glucal is used.
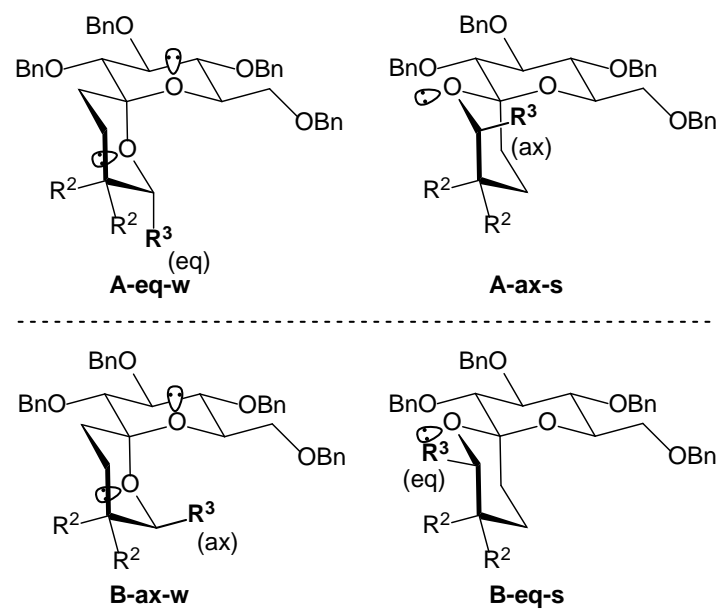

Figure 3. Spirocyclized products.

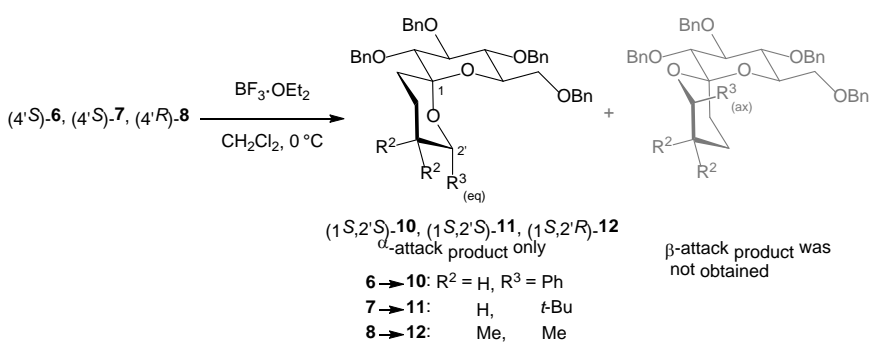

Scheme 4. Spirocyclization of exo-glucals (matched pair).

Table 2. Spirocyclization of exo-glucals (matched pair).

\begin{tabular}{cccccc}
\hline Entry & exo-Glucal & $\mathrm{R}^{2}$ & $\mathrm{R}^{3}$ & Spiroketal & Yield/\% \\
\hline$c f$. & $\mathbf{5}$ & $\mathrm{Me}$ & $\mathrm{H}$ & $(1, S)-9$ & 91 \\
1 & $\left(4^{\prime},\right)^{\prime}-6$ & $\mathrm{H}$ & $\mathrm{Ph}$ & $\left(1 S, 2^{\prime} S\right)-10$ & 99 \\
2 & $\left(4^{\prime} \mathrm{S}\right)-7$ & $\mathrm{H}$ & $\mathrm{t}-\mathrm{Bu}$ & $\left(1 \mathrm{~S}, 2^{\prime} \mathrm{S}\right)-11$ & 94 \\
3 & $\left(4^{\prime} \mathrm{R}\right)-8$ & $\mathrm{Me}$ & $\mathrm{Me}$ & $\left(1 \mathrm{~S}, 2^{\prime} \mathrm{R}\right)-12$ & 95 \\
\hline
\end{tabular}

We accomplished spirocyclizations using (4'S)-6 and (4'R)-6 under similar reaction conditions in order to clarify how C-4' chirality influences the stereoselectivity of spiro quaternary carbon of the cyclized product. According to our hypothesis, it is predicted that (4'S)-6 can be converted into (1S,2'S)-10 exclusively via an $\alpha$-attack to the oxocarbenium faces, since the pair of the chiral D-glucopyranose environment and the C-4' $S$ chirality is matched for an $\alpha$-attack. ${ }^{8}$ On the other hand, it is suspected that ( $\left.4^{\prime} R\right)-\mathbf{6}$ can be converted into a mixture of $\left(1 R, 2^{\prime} R\right)$ - and $\left(1 S, 2^{\prime} R\right)-10$ because of a mismatched chiral pair of D-glucopyranose (favored for $\alpha$-attack) and C-4' $R$ chirality (favored for $\beta$-attack). ${ }^{8}$ As a result, (4'S)-6 was converted into (1S,2'S)-10 as a single isomer in 99\% yield. Surprisingly, (4'R)-6 was also converted into $\left(1 R, 2^{\prime} R\right)-10$ as a single isomer in $88 \%$ yield. ${ }^{10}$ Thus, the spirocyclizations from both epimers of 6 proceeded stereoselectively with high efficiency to produce different spiroketal isomers. The structures of the produced spiroketal isomers $\left(1 S, 2^{\prime} S\right)$ - and $\left(1 R, 2^{\prime} R\right)-\mathbf{1 0}$ supported our hypothesis on the cyclization mechanism; the stereochemistry of the spiro quaternary carbon of the product $\mathbf{1 0}$ could be induced by the C-4' chirality despite the existence of chiral D-glucopyranose. It should be noted that the stereocontrolling ability of C-4' $R$ chirality ( $\beta$-attack $\rightarrow(1 R)$-isomer) overcomes that of a chiral D-glucopyranose environment ( $\alpha$-attack $\rightarrow(1 S)$-isomer). ${ }^{11}$ We also attempted spirocyclizations using (4'S)- and (4'R)-7 


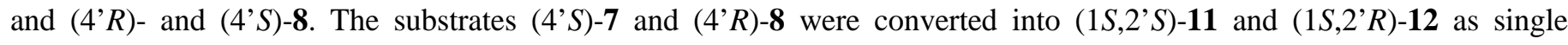
isomers in 94\% and 95\% yields, respectively, while (4' $R$ )-7 and (4'S)-8 were converted into (1R,2'R)-11 and (1R,2' $S)$-12 as single isomers in $99 \%$ and $97 \%$ yields, respectively. In complete agreement with our speculation, the produced spiroketal structures were similarly determined by the stereochemistry at C-4' of 6-8. We confirmed the produced spiroketal structures by measurements of the NOE interactions shown in Figure 4.

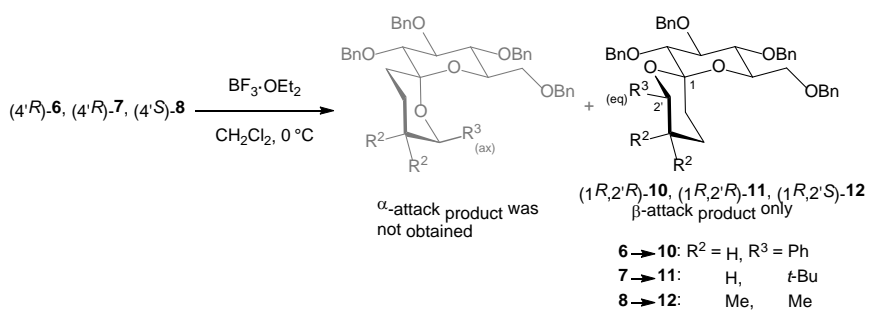

Scheme 5. Spirocyclization of exo-glucals (mismatched pair).

Table 3. Spirocyclization of exo-glucals (mismatched pair).

\begin{tabular}{llllll}
\hline Entry & exo-Glucal & $\mathrm{R}^{2}$ & $\mathrm{R}^{3}$ & Spiroketal & Yield/\% \\
\hline 1 & $\left(4^{\prime} R\right)-6$ & $\mathrm{H}$ & $\mathrm{Ph}$ & $\left(1 R, 2^{\prime} R\right)-10$ & 88 \\
2 & $\left(4^{\prime} R\right)-7$ & $\mathrm{H}$ & $t \mathrm{Bu}$ & $\left(1 R, 2^{\prime} R\right)-11$ & 99 \\
3 & $\left(4^{\prime} S\right)-8$ & $\mathrm{Me}$ & $\mathrm{Me}$ & $\left(1 R, 2^{\prime} S\right)-12$ & 97 \\
\hline
\end{tabular}
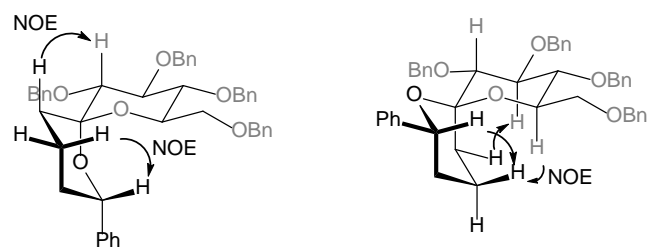

Figure 4. NOE measurements of spirocyclization products

In summary, we investigated a synthetic approach to spiro[5.5]ketals from exo-glucal derivatives having a C-4' hydroxyl group in the side chain by spirocyclization based on intramolecular glycosylation. We achieved the facile synthesis of the exo-glucal derivatives for spirocyclization and elucidated the effect of the C-4' chirality on the spirocyclization properties using the both C-4' epimeric isomers. It can be concluded that the effect of the C-4' chirality of the exo-glucals enabled stereocontrolled cyclizations. We accomplished highly stereoselective synthesis of both $\alpha$ - and $\beta$-glucoside spiroketals. It is noteworthy that the $\beta$-glucoside was obtained with high stereoselectivity from one epimer of exo-glucal, which was a ketopyranose equivalent.

General experimental procedure for spirocyclization is as follows: To a solution of exo-glucal ( $0.26 \mathrm{mmol})$ in dichloromethane $(3 \mathrm{~mL})$ was added boron trifluoride etherate $(0.26 \mathrm{mmol})$ at $0{ }^{\circ} \mathrm{C}$ under an argon atmosphere. After stirring for $1 \mathrm{~h}$ at that temperature, the reaction mixture was poured into a saturated aqueous solution of sodium hydrogencarbonate and extracted three times with ethyl acetate. Combined organic layer was washed with water, dried over anhydrous sodium sulfate, and evaporated under reduced pressure. Purification by silica gel chromatography (hexane/ethyl acetate $=4: 1$ ) afforded spiroketal product. 
1. (a) Lin, C.-H.; Lin, H.-C.; Yang, W.-B. Current Topics in Med. Chem. 2005, 5, 1431-1457; (b) Taillefumier, C.; Chapleur, Y. Chem. Rev. 2004, 104, 263-292.

2. (a) Namme, R.; Mitsugi, T.; Takahashi, H.; Shiro, M.; Ikegami, S. Tetrahedron 2006, 62, 9183-9192; (b) Hsu, S.-J.; Lin, H.-C.; Lin, C.-H.; Carbohydr. Res. 2006, 341, 1428-1437; (c) Lin, H.-C.; Du, W.-P.; Chang, C.-C.; Lin, C.-H. Tetrahedron Lett. 2005, 46, 5071-5076; (d) Namme, R.; Mitsugi, T.; Takahashi, H.; Ikegami, S. Tetrahedron Lett. 2005, 46, 3033-3036; (e) Lin, H.-C.; Chang, C.-C.; Chen, J.-Y.; Lin, C.-H. Tetrahedron: Asymmetry 2005, 16, 297-301; (f) Lin, H.-C.; Yang, W.-B.; Gu, Y.-F.; Chen, C.-Y.; Wu, C.-Y.; Lin, C.-H. Org. Lett. 2003, 5, 1087-1089; (g) Sharma, G. V. M.; Rakesh; Chander, A. S.; Reddy, V. G.; Rao, M. H. V. R.; Kunwar, A. C. Tetrahedron: Asymmetry 2003, 14, 2991-3004; (h) Chang, C.-F.; Yang, W.-B.; Chang, C.-C.; Lin, C.-H. Tetrahedron Lett. 2002, 43, 6515-6519; (i) Li, X.; Ohtake, H.; Takahashi, H.; Ikegami, S. Synlett 2001, 1885-1888; (j) Li, X.; Ohtake, H.; Takahashi, H.; Ikegami, S. Tetrahedron 2001, 57, 4283-4295.

3. Spirocyclization from exo-glycals to spiro[5.5]ketals: (a) Corbet, M.; Bourdon, B.; Gueyrard, D.; Goekjian, P. G. Tetrahedron Lett. 2008, 49, 750-754; Spirocyclization from exo-glycals to spiro[5.4]ketals: (b) Paterson, D. E.; Griffin, F. K.; Alcaraz, M.-L.; Taylor, R. J. K. Eur. J. Org. Chem. 2002, 1323-1336; (c) Alcaraz, M.-L.; Griffin, F. K.; Paterson, D. E.; Taylor, R. J. K. Tetrahedron Lett. 1998, 39, 8183-8186; (d) Tomooka, K.; Nakamura, Y.; Nakai, T. Synlett 1995, 321-322; Spirocyclization from exo-glycals to spiro[4.4]ketals: (e) Yang, W.-B.; Chang, C.-F.; Wang, S.-H.; Teo, C.-F.; Lin, C.-H. Tetrahedron Lett. 2001, 42, 4657-4660; Spirocyclizaion from endo-glycals to spiro[5.5]ketals: (f) Fuwa, H.; Sasaki, M. Org. Lett. 2008, 10, 2549-2552; (g) Conway, J. C.; Urch, C. J.; Quayle, P.; Xu, J. Synlett 2006, 776-780.

4. (a) Aho, J. E.; Pihko, P. M.; Rissa, T. K. Chem. Rev. 2005, 105, 4406-4440; (b) Perron, F.; Albizati, K. F. Chem. Rev. 1989, 89, 1617-1661.

5. Yamanoi, T.; Nara, Y.; Matsuda, S.; Oda, Y.; Yoshida, A.; Katsuraya, K.; Watanabe, M. Synlett 2007, 785-789.

6. Ohtani, I.; Kusumi, T.; Kashman, Y.; Kakisawa, H. J. Am. Chem. Soc. 1991, 113, 4092-4096.

7. Toshima, K. In Handbook of Chemical Glycosilation; Demchenco, A. V., Ed.; Wiley-VCH: Weinheim, 2008; pp 449469.

8. For review: Masamune, S.; Choy, W.; Petersen, J. S.; Sita, L. R. Angew. Chem., Int. Ed. Engl. 1985, 24, 1-30; For example, Mikami, K.; Yoshida, A. Tetrahedron Lett. 1994, 35, 7789-7792.

9. Pothier, N.; Goldstein, S.; Deslongchamps, P. Helv. Chim. Acta 1992, 75, 604-620.

10. (a) Deslongchamps, P.; Rowan, D. D.; Pothier, N.; Sauvé, G.; Saunders, J. K. Can. J. Chem. 1981, 59, 1105-1121; (b) For review: Deslongchamps, P. Stereoelectronic effects in organic chemistry; Pergamon: Oxford,1983. Fuwa et al. have recently reported a spirocyclization process to spiro[5.5]ketals from the endo-glucals having a C-4' stereocenter. The endo-glucals without a C-2 benzyloxy group indicated the cyclization stereospecificities different from those observed in our investigation. See ref. 3f. 